\title{
The occurrence and predictive factors of sleep paralysis in university students
}

\author{
This article was published in the following Dove Press journal: \\ Neuropsychiatric Disease and Treatment \\ 14 November 2016 \\ Number of times this article has been viewed
}

\author{
Monika Lišková ${ }^{1,2}$ \\ Denisa Janečková! \\ Lucie Klůzová Kráčmarováa \\ Karolína Mladá \\ Jitka Bušková ${ }^{1,2}$ \\ 'Institute of Sleep Medicine, National \\ Institute of Mental Health, Klecany, \\ ${ }^{2}$ Third Faculty of Medicine, Charles \\ University, Prague, ${ }^{3}$ Olomouc \\ University Social Health Institute, \\ Palacky University, Olomouc, \\ Czech Republic
}

\begin{abstract}
The aim of the present study was to assess the occurrence and predictive factors of sleep paralysis (SP) in Czech university students. Our sample included 606 students who had experienced at least one episode of SP. The participants completed an online battery of questionnaires involving questionnaires focused on describing their sleep habits and SP episodes, the 18-item Boundary Questionnaire (BQ-18), the Modified Tellegen Absorption Scale (MODTAS), the Dissociative Experience Scale Taxon, the Beck Depression Inventory II and the State-Trait Anxiety Inventory. The strongest predictive factor for the frequency of SP episodes was nightmares. The strongest predictive factor for the intensity of fear was dream occurrences. In our study sample, SP was more common in women than in men. Those who scored higher in BQ-18 experienced more often pleasant episodes of SP and those who scored higher in MODTAS were more likely to experience SP accompanied with hallucinations. While $62 \%$ of respondents answered that their SP was accompanied by intense fear, $16 \%$ reported that they experienced pleasant feelings during SP episodes. We suggest that not only the known rapid eye movement sleep dysregulation but also some personality variables may contribute to the characteristics of SP.
\end{abstract}

Keywords: sleep paralysis, absorption, personality boundaries, dissociation, nightmares

\section{Introduction}

Isolated sleep paralysis (SP) is a recurrent inability to move the body at sleep onset or upon awakening from sleep lasting seconds to a few minutes. The episodes cause clinically significant distress. The episodes cannot be better explained by another sleep disorder, mental disorder, medical condition, medication, or substance use. ${ }^{1}$

The etiology is not known yet. SP mostly occurs in young adulthood, but there is a lifetime prevalence. ${ }^{2,3}$ Almost $8 \%$ of general population, $28 \%$ of students and $32 \%$ of psychiatric patients experience at least one episode of SP during their lives. ${ }^{2}$ The sooner the SP begins, the more frequent the episodes are. ${ }^{4}$

Experiencing SP is usually unpleasant. Fear has been reported in $90 \%$ of the student sample. ${ }^{5}$ In psychiatric outpatients, the clinically significant level of fear was found in $69 \%$ of cases. ${ }^{6}$ According to Cheyne, ${ }^{7}$ fear arises mostly from the reaction to an inability to move or the hallucinatory content. Approximately $70 \%$ of SP episodes are accompanied by hallucinations, ${ }^{8,9}$ although some studies found their simultaneous occurrence only in 33\%. ${ }^{10}$ Mostly, we distinguish 3 types of hallucinations - intruders, incubus and vestibular-motor hallucinations. Incubus and intruder hallucinations are correlated with each other and with intense fear. Vestibular-motor hallucinations can be associated with blissful and erotic feelings. ${ }^{11,12}$

The aim of our study was to assess the occurrence and predictive factors of SP in Czech university students. We were especially interested whether personality traits
Institute of Sleep Medicine, Nationa Institute of Mental Health, Topolova 748, Klecany 180 00, Czech Republic

Tel +420283088203

Fax +420 283088420

Email monika.liskova@nudz.cz
Neuropsychiatric Disease and Treatment 2016:12 2957-2962

2957

Dovepress if in 0

http://dx.doi.org/10.2147/NDT.S115629 (c) (1) (-) 2016 Lišková et al. This work is published and licensed by Dove Medical Press Limited. The full terms of this license are available at https://www.dovepress.com/terms.php cc. ${ }_{\mathrm{BY}} \mathrm{NC}$ and incorporate the Creative Commons Attribution - Non Commercial (unported, v3.0) License (http://creativecommons.org/licenses/by-nc/3.0/). By accessing the work you hereby accept the Terms. Non-commercial uses of the work are permitted without any further permission from Dove Medical Press Limited, provided the work is properly attributed. For permission for commercial use of this work, please see paragraphs 4.2 and 5 of our Terms (https://www.dovepress.com/terms.php). 
play a role in the frequency of SP rather than external factors such as irregular sleep patterns, sleep deprivation and stressful events.

\section{Methods}

The study was designed as a cross-sectional questionnairebased descriptive study and was carried out from February 2015 to June 2015. The study sample consisted of Czech undergraduate and postgraduate students who answered to an advertisement for the study in university social media. All of them participated voluntarily and anonymously. Our criteria for inclusion were to have experienced SP at least once ("Have you ever experienced a transitional state of inability to move accompanied by hallucinations, when you can't move or scream, during falling asleep or waking up?") and currently being the student in present or distant form of study in undergraduate or postgraduate university level. We excluded those participants who did not fill out the whole questionnaire battery and those who answered that they suffer from another sleep disorder. We did not exclude participants with psychiatric disorders, due to our interest in the connection between SP with anxiety and depressive states. Written informed consent was obtained from all the participants. The study was approved by the Ethic Commission of National Institute of Mental Health and was conducted according to the Declaration of Helsinki.

\section{Instrumental tools}

We used a battery of questionnaires divided into 6 parts. We designed a questionnaire to determine the participant's sleep habits (the length of sleep during workdays and on weekends, the amount of sleep they need to feel refreshed, presence and frequency of dreams and nightmares). Regarding the SP episodes, we asked for their age at the time of first occurrence, frequency and duration of episode, daytime occurrence, type of hallucinations, sleeping posture, factors that helped to stop the episode, intensity of fear and pleasantness of episodes.

\section{The 18-item Boundary Questionnaire (BQ-18)}

The BQ-18 is a short version of the Boundary Questionnaire, ${ }^{13}$ a self-administered questionnaire to measure boundaries of personality. Total score ranges from 0 to 64 . The higher the score is, the thinner the boundaries are. People with thin boundaries have a blurred distinction between all aspects of their lives and are open in many ways. People with thick boundaries are solid, well-defended and have a clear distinction in all aspects of their lives. ${ }^{14}$

\section{The Modified Tellegen Absorption Scale (MODTAS)}

Jamieson ${ }^{15}$ modified the original Tellegen Absorption Scale (TAS). Absorption is a latent personality construct, initially described by Tellegen and Atkinson ${ }^{16}$ as a

Disposition for having episodes of 'total' attention that fully engage someone's representational (ie, perceptual, enactive, imaginative, and ideational) resources. ${ }^{16}$

The total score ranges from 0 to 136 . The higher the score is, the higher the ability of absorption the people have.

\section{The Dissociative Experience Scale Taxon (DES-T)}

DES-T ${ }^{17,18}$ is an 8-item subscale version of the full-scale DES developed by Bernstein and Putman in $1986 .{ }^{19}$ The DES-T measures pathological dissociation. DES-T consists of 8 statements (descriptions of situations), and the subjects should indicate how often they experience the described situations $(0 \%, 10 \%, 20 \%, \ldots 100 \%)$. Total scores are calculated by averaging the score in the 8 items. Higher scores indicate higher degree of dissociation. Dissociation occurs to some degree in normal populations. ${ }^{17}$ Bernstein and Putman ${ }^{19}$ described dissociation as "the lack of normal integration of thoughts, feelings, and experiences into the stream of consciousness and memory".

\section{State-Trait Anxiety Inventory (STAI)}

$\mathrm{STAI}^{20}$ is a 40 -item scale to measure anxiety. It consists of 2 parts - the first part (STAI-S) evaluates the current state of anxiety, ie, how the participants feel now. The second part (STAI-T) measures anxiety as a personality trait, ie, stable individual differences in anxiety proneness including general state of calmness and confidence. The score range for each subtest is from 20 to 80 . Higher scores indicate greater anxiety. ${ }^{21}$

\section{Beck Depression Inventory II (BDI II)}

BDI II is an improved form of BDI developed by Beck et al in $1961 .{ }^{22}$ BDI II is a 21-item inventory to measure depressive symptoms. The answers are chosen from 4 options ranging from 0 (not present) to 3 (severe). Total score ranges from 0 to 63 ; the higher the score, the more severe the signs of depression are. ${ }^{23}$

\section{Statistical analysis}

For data analysis, we used $\chi^{2}$ tests for nominal variables with a significance level of 0.05 . The Mann-Whitney $U$-test was conducted to compare frequency of SP episodes between genders. The Spearman's rank correlation coefficient was used to compute the strength of relationship between frequency of 
SP (or intensity of fear) and scores of questionnaires or other ordinal data. $t$-Test for independent samples was performed to compare questionnaire scores of group with or without pleasant feelings in SP or hallucinations. A multinomial logistic regression analysis was used to find factors affecting the frequency of SP and the intensity of fear. For the need of logistic regression analysis, we connected 6 levels of frequency and 5 levels of intensity of fear into groups frequent/not frequent and fearful/not fearful. Statistical analyses were conducted in STATISTICA Version 12 and IBM SPSS Statistics 23.

\section{Results}

The study sample consisted of 1,351 undergraduate and postgraduate students, 606 of them met the inclusion criteria and were included in the analysis. Of them, 169 (28\%) were men and $437(72 \%)$ women. Mean age of the sample was 23.3 years ( $\mathrm{SD}=2.9$ years). A total of 17 participants were diagnosed with psychiatric disorder (depression [ $\mathrm{n}=5]$, anxiety $[\mathrm{n}=6]$, combination of depression and anxiety [ $\mathrm{n}=2]$, eating disorder $[\mathrm{n}=1]$, panic disorder $[\mathrm{n}=1]$, bipolar disorder $[\mathrm{n}=1]$ and combination of social phobia and panic disorder $[n=1]$ ).

The most represented fields of studies in our sample were social sciences $(n=191 ; 32 \%)$, followed by natural sciences $(n=84 ; 16 \%)$, technical sciences $(n=55 ; 9 \%)$, medical sciences $(n=45 ; 7 \%)$, art schools $(n=42 ; 7 \%)$ and others and combinations $(n=42 ; 7 \%)$. A total of $42 \%(n=147)$ of the participants did not answer the question about their field of study.

The mean age of the first SP episode was 17 years, and $24 \%(n=146)$ of participants experienced SP episodes before the age of 15 years. SP was more common in women than in men $(z=2.28 ; P=0.036)$. The most frequent SP duration was between few seconds and 2 minutes $(n=324 ; 54 \%)$; shorter episodes were referred to in $22 \%$ of the sample $(n=133)$. A total of $20 \%$ of participants reported episodes between 2 and 5 minutes $(n=120)$ and $5 \%(n=28)$ referred to episodes longer than 5 minutes. The SP episodes typically occurred in the supine position $(\mathrm{n}=383 ; 63 \%)$ rather than in the lateral position $(n=143 ; 24 \%)$, prone position $(n=50 ; 8 \%)$ or others $(n=30 ; 5 \%)$. A familial form of SP was present in $6 \%$ of participants. A total of $83 \%(n=502)$ of our respondents reported that their SP episodes were always characterized by a complete inability to move, typically accompanied by hallucinations ( $\mathrm{n}=475 ; 78 \%)$. The most common was a combination of different sensory modalities ( $44 \%$ cases). The most typical kind of hallucination was visual ( $11 \%)$, followed by auditory $(4 \%)$ and feelings of the sensed presence (4\%).

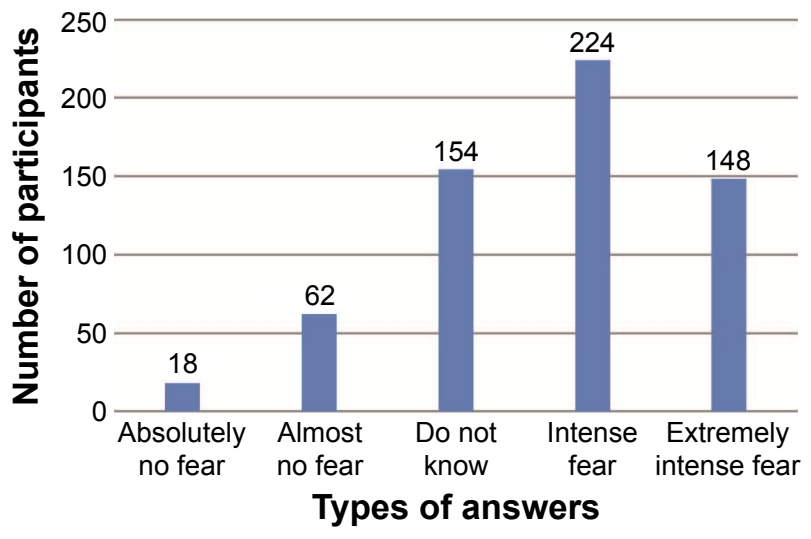

Figure I The reported intensity of fear during sleep paralysis.

In most cases, $\mathrm{SP}$ occurred several times a year $(\mathrm{n}=225$; $37 \%)$. SP occurred less than a few times a year in 199 cases (33\%) and only 2 participants reported daily episodes. SP mostly occurred throughout the night $(\mathrm{n}=212 ; 35 \%)$, less frequently during sleep onset $(\mathrm{n}=175 ; 29 \%)$, around morning awakening $(\mathrm{n}=130 ; 21 \%)$ or during daytime naps $(\mathrm{n}=89 ; 15 \%)$.

$\mathrm{SP}$ is generally regarded as a frightening event (Figure 1), but our results also show frequent pleasant episodes $(n=95$, $16 \%$; Figure 2). A total of $40 \%(n=245)$ of participants were able to define a trigger (stressful events $23 \%$, lack of sleep $9 \%$, fatigue $4 \%$, watching TV and horrors $2 \%$, daytime naps $2 \%$ and the full moon 2\%) to their SP episodes. According to our respondents, SP episodes typically terminated spontaneously $(48 \%, \mathrm{n}=292)$ or by intense effort to move $(38 \%, n=228)$.

After fulfilling the criteria for $\chi^{2}$ tests, we calculated Spearman's rank correlation. There were 2 correlations found between the frequency of SP and scores in questionnaires ( $r=0.092$ and 0.082 , respectively). Although their values are

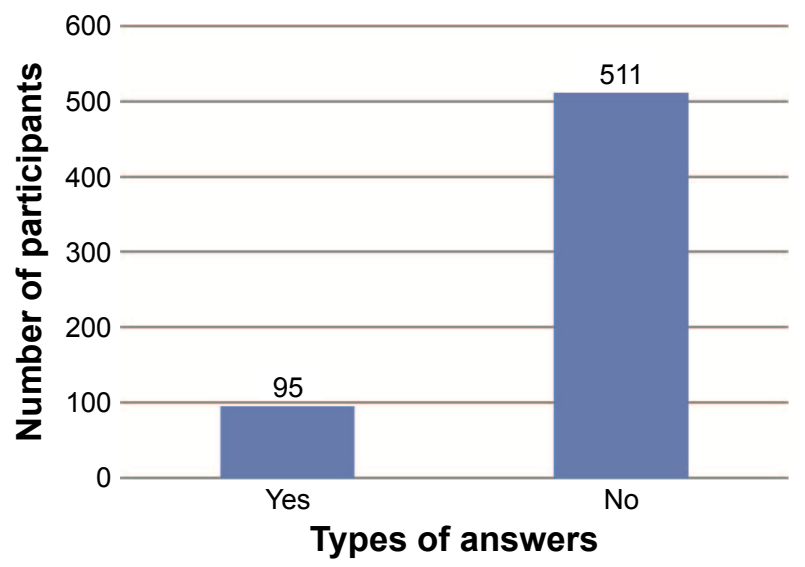

Figure 2 Presence of pleasant feelings in SP in the study sample. Abbreviation: SP, sleep paralysis. 
Table I Predictive factors of the frequency of sleep paralysis

\begin{tabular}{lll}
\hline Predictive factors & Sig & OR \\
\hline $\begin{array}{lll}\text { Gender } \\
\text { Men }\end{array}$ & $\mathbf{0 . 0 0 1}$ & $\mathbf{0 . 5 2}$ \\
Women & & $\mathrm{I}$ \\
Open eyes & & \\
$\quad$ Yes & 0.360 & 0.82 \\
No & 0.921 & $\mathrm{I} .02$ \\
Do not know & & $\mathrm{I}$ \\
Nightmares & & \\
Yes & $\mathbf{0 . 0 1 9}$ & $\mathbf{1 . 5 6}$ \\
No & & $\mathrm{I}$ \\
Sleep position & & 1.18 \\
Supine & 0.703 & 2.47 \\
Lateral & 0.049 & 0.71 \\
Prone & 0.555 & $\mathrm{I}$ \\
Other & &
\end{tabular}

Note: Values in bold indicate statistically significant data $(P<0.05)$.

Abbreviations: OR, odds ratio; Sig, significance.

low, the test considered them as significant and confirmed that the score in DES-T and the score in STAI-S were positively associated with more frequent SP episodes. Correlations between other questionnaires and the frequency of SP were not significant. Using $\chi^{2}$ tests and Spearman's rank correlations, no significant relationships were found between the frequency of SP and the form or study program, sleep duration, dream occurrence, timing of episodes, inability to move and the length of the SP episodes. Intensity of fear was not correlated with the questionnaire scores. We found higher BQ-18 score in subjects experiencing pleasant $\mathrm{SP}(\mathrm{t}=3.44 ; P<0.001)$. A significant difference was found in the score of MODTAS for SP accompanied by hallucinations ( $\mathrm{t}=2.435 ; P=0.015$ ).

Based on the results of $\chi^{2}$ tests with a significance level of 0.05 , we conducted multinomial logistic regression analysis to find predictive factors of the frequency of SP (Table 1) and the intensity of fear (Table 2). The strongest predictive factor for the SP frequency was nightmares (odds ratio $[\mathrm{OR}]=1.56 ; P=0.019)$, and a protective factor was the male gender ( $\mathrm{OR}=0.52 ; P=0.001)$. The strongest predictive factor for the intensity of fear was the sleep with recalled dreams, many dreams and a few dreams, respectively $(\mathrm{OR}=3.98$; $P=0.003$ and $\mathrm{OR}=3.95 ; P=0.004)$.

\section{Discussion}

According to our results, most common SP experience in university students was only several times a year, which corresponds with the assumed distribution of SP in general population and with the presumption that $\mathrm{SP}$ is quite a common phenomenon in its isolated form, although the recurrent experience is rare. In our study, SP occurred more often in women than men, as shown similarly in previous studies; ${ }^{2}$
Table 2 Predictive factors of the intensity of fear

\begin{tabular}{|c|c|c|}
\hline Predictive factors & Sig & OR \\
\hline \multicolumn{3}{|l|}{ Gender } \\
\hline Men & 0.029 & 1.53 \\
\hline Women & & 1 \\
\hline \multicolumn{3}{|l|}{ Sleep with dreams } \\
\hline Sleep with many recalled dreams & 0.003 & 3.98 \\
\hline Sleep with a few recalled dreams & 0.004 & 3.95 \\
\hline Dreamless sleep & & I \\
\hline \multicolumn{3}{|l|}{ SP occurrence } \\
\hline SP occurrence during falling asleep & 0.1 & 1.57 \\
\hline SP occurrence during night & 0.004 & 2.24 \\
\hline SP occurrence during awakening & $0.41 \mathrm{I}$ & 0.79 \\
\hline SP occurrence during day nap & & I \\
\hline \multicolumn{3}{|l|}{ Hallucinations } \\
\hline Yes & 0.000 & 2.274 \\
\hline No & & 1 \\
\hline \multicolumn{3}{|l|}{ Open eyes } \\
\hline Yes & 0.004 & 1.96 \\
\hline No & 0.001 & 2.18 \\
\hline Do not know & & 1 \\
\hline \multicolumn{3}{|l|}{ Pleasant sleep paralysis } \\
\hline Yes & 0.000 & 0.18 \\
\hline No & & 1 \\
\hline \multicolumn{3}{|l|}{ Inability to move } \\
\hline Yes & 0.000 & 2.67 \\
\hline No & & I \\
\hline
\end{tabular}

Note: Values in bold indicate statistically significant data $(P<0.05)$. Abbreviations: OR, odds ratio; SP, sleep paralysis; Sig, significance.

however, this result cannot be conclusively interpreted because more women participated in the study.

We found that the mean age at the time of the first SP occurrence was 17 years and $24 \%$ of respondents stated that SP started even before the age of 15 years. We suggest that SP in university students is not the result of actual irregular sleep patterns or sleep deprivation, which is common in this population. ${ }^{24}$ The age of onset of SP corresponds to the age of the beginning of narcolepsy ${ }^{25}$ and could be related to antecedent rapid eye movement (REM) sleep dysregulation.

Another interesting finding is that most of our participants reported a SP occurrence throughout the night. Current scientific literature provides inconsistent results with respect to typical timing of SP episodes. SP episodes have been reported to be more prevalent at sleep onset, ${ }^{26}$ during the first 2 hours after sleep onset ${ }^{27}$ as well as at sleep offset. ${ }^{3}$ In the study by Cheyne, ${ }^{7}$ the most frequent timing was a combination of time (beginning of sleep, middle of the night and end of sleep). This discrepancy might be partially due to methods of questioning about the timing of SP episodes. For example, when questioning only about the timing of SP episodes either while falling asleep or while waking up, ${ }^{26}$ waking up could be in the morning or in the middle of the night.

SP is typically connected with unpleasant feelings and fear. ${ }^{1}$ Accordingly, $69 \%$ of our participants answered that SP 
was accompanied by intense or extreme fear, whereas only $3 \%$ experienced absolutely no fear (Figure 1 ). We found that predictive factors for the intensity of fear had the presence of dreams, the inability to move, hallucinations and occurrence of SP in the middle of the night. According to Cheyne's hypothesis, ${ }^{7}$ the intensity of hallucinations in SP could be stronger in the middle of the night and in the morning hours. We would expect that the intensity of hallucinations would predict fear related to SP episodes not only in the middle of the night but also in the morning hours.

Interestingly, we found that $16 \%$ of our participants also experienced pleasant feelings during SP episodes (Table 2) that were rarely mentioned earlier. ${ }^{4,28}$ Parker and Blackmore ${ }^{28}$ found that $2 \%$ of women and $8 \%$ of men experienced happiness during their SP episodes. According to Cheyne, ${ }^{4}$ pleasant feelings could be positively associated with vestibular-motor hallucinations. Our data show that participants who describe SP as pleasant have thinner boundaries, which means that they are open to new experiences. These participants are more creative with rich fantasies and are more affected by external and internal stimuli including dreams, which tend to be more bizarre too..$^{14,29,30}$ We suggest that the positive content of SP episodes and high frequency of dreams might be used in psychotherapy for SP.

Using a multinomial logistic regression analysis, the strongest predictive factor for the frequency of SP seems to be the presence of nightmares. According to Hall and Van de Castle, ${ }^{31}$ positive emotions are usually mentioned in only onethird of dream reports and two-thirds of emotions are described as unpleasant. Nightmares are connected with unpleasant feelings. When nightmares are looked at only from the emotional aspect, the quality of emotions experienced during nightmares is very similar to that experienced during SP episodes. Fear is dominant in both the states. Parker and Blackmore ${ }^{28}$ found that women reported SP as more fearful, felt more victimized and experienced more sexual activity. Kotorii et $\mathrm{al}^{32}$ found also a strong correlation between SP and dreams and nightmares. However, our results did not show a significant correlation between the SP frequency and fear intensity.

McNally and Clancy ${ }^{9}$ using DES Questionnaire and Absorption Scale in their study showed that people who experience SP score higher on DES and Absorption scale than those who have not experienced SP. Watson ${ }^{33}$ found a positive correlation between dissociative score and nightmares, dying in a dream, sensing someone around, flying dreams, hypnopompic and hypnagogic imagery. Similarly, we found a positive correlation between score on DES-T and the frequency of SP episodes. We have not seen a significant relationship between MODTAS, BQ-18 and STAI-T and the frequency of SP.
Although students are thought to be one of the most likely populations to experience SP, our limitations to this population could lead to misrepresenting the results, because SP can occur at any age. We only used self-administered questionnaires that could also misrepresent the results, for example, due to an altered self-image or the social desirability effect. We did not have a control group, so we cannot compare our results of participants who experienced SP with those who did not experience it. Our study design was retrospective, which could influence the data. Further studies should focus on the pleasant aspects of SP and the psychotherapy of SP.

\section{Conclusion}

In our sample of 606 university students, we found that SP is more frequent in women and occurs mostly several times a year. The strongest predictive factor for the frequency of SP episodes is nightmares. A total of $69 \%$ of respondents reported that SP was accompanied by intense or extreme fear, but $16 \%$ reported that they experienced pleasant feelings during episodes of SP. The strongest predictive factor for the intensity of fear is the occurrence of dreams. People who score higher in BQ-18 Questionnaire experience more often pleasant feelings during SP episodes. People who score higher in MODTAS experience more frequently SP episodes with hallucinations.

We suggest that not only the known REM sleep dysregulation influences SP but also some personality variables may contribute to the characteristics of SP.

\section{Acknowledgments}

This study is a result of the research funded by the project Nr. LO1611 with a financial support from the MEYS under the NPU I program. This publication was supported by the project "National Institute of Mental Health (NIMH-CZ)" grant number ED2.1.00/03.0078 and the European Regional Development Fund. This publication was further supported by the project "PRVOUK P34".

\section{Disclosure}

The authors report no conflicts of interest in this work.

\section{References}

1. American Academy of Sleep Medicine. International Classification of Sleep Disorders. Darien, IL: American Academy of Sleep Medicine; 2014.

2. Sharpless BA, Barber JP. Lifetime prevalence rates of sleep paralysis: a systematic review. Sleep Med Rev. 2011;15(5):311-315.

3. Ohayon MM, Zulley J, Guilleminault C, Smirne S. Prevalence and pathologic associations of sleep paralysis in the general population. Neurology. 1999;52(6):1194-1200.

4. Cheyne JA. Sleep paralysis episode frequency and number, types, and structure of associated hallucinations. J Sleep Res. 2005;14(3):319-324. 
5. Cheyne JA, Newby-Clark IR, Rueffer SD. Relations among hypnagogic and hypnopompic experiences associated with sleep paralysis. J Sleep Res. 1999;8(4):313-317.

6. Sharpless BA, McCarthy KS, Chambless DL, Milrod BL, Khalsa SR, Barber JP. Isolated sleep paralysis and fearful isolated sleep paralysis in outpatients with panic attacks. J Clin Psychol. 2010;66(12): 1292-1306.

7. Cheyne JA. Situational factors affecting sleep paralysis and associated hallucinations: position and timing effects. J Sleep Res. 2002;11(2): 169-177.

8. Jimenez-Genchi A, Avila-Rodriguez VM, Sanchez-Rojas F, Terrez BE, Nenclares-Portocarrero A. Sleep paralysis in adolescents: the 'a dead body climbed on top of me' phenomenon in Mexico. Psychiatry Clin Neurosci. 2009;63(4):546-549.

9. McNally RJ, Clancy SA. Sleep paralysis, sexual abuse, and space alien abduction. Transcult Psychiatry. 2005;42(1):113-122.

10. Jalal B, Hinton DE. Rates and characteristics of sleep paralysis in the general population of Denmark and Egypt. Cult Med Psychiatry. 2013; 37(3):534-548.

11. Cheyne JA, Rueffer SD, Newby-Clark IR. Hypnagogic and hypnopompic hallucinations during sleep paralysis: neurological and cultural construction of the night-mare. Conscious Cogn . 1999;8(3):319-337.

12. Cheyne JA. The ominous numinous - sensed presence and 'other' hallucinations. J Conscious Stud. 2001;8(5-7):133-150.

13. Hartmann E. Boundaries of dreams, boundaries of dreamers: thin and thick boundaries as a new personality measure. Psychiatr J Univ Ott. 1989; 14(4):557-560.

14. Kunzendorf RG, Hartmann E, Cohen R, Cutler J. Bizarreness of the dreams and daydreams reported by individuals with thin and thick boundaries. Dreaming. 1997;7(4):265.

15. Jamieson $\mathrm{G}$. The modified Tellegen absorption scale: a clearer window on the structure and meaning of absorption. Aust J Clin Exp Hypn. 2005; 33:119-139.

16. Tellegen A, Atkinson G. Openness to absorbing and self-altering experiences ("absorption"), a trait related to hypnotic susceptibility. J Abnorm Psychol. 1974;83(3):268-277.

17. Waller NG, Putnam FW, Carlson EB. Types of dissociation and dissociative types: a taxometric analysis of dissociative experiences. Psychol Methods. 1996;1(3):300-321.
18. Waller NG, Ross CA. The prevalence and biometric structure of pathological dissociation in the general population: taxometric and behavior genetic findings. J Abnorm Psychol. 1997;106(4):499-510.

19. Bernstein EM, Putnam FW. Development, reliability, and validity of a dissociation scale. J Nerv Ment Dis. 1986;174(12):727-735.

20. Spielberger CD, Gorsuch R. State-Trait Anxiety Inventory for Adults: Manual and Sample: Manual, Instrument and Scoring Guide. Palo Alto, CA: Consulting Psychologists Press; 1983.

21. Julian LJ. Measures of anxiety: State-Trait Anxiety Inventory (STAI), Beck Anxiety Inventory (BAI), and Hospital Anxiety and Depression ScaleAnxiety (HADS-A). Arthritis Care Res (Hoboken). 2011;63(suppl 11): S467-S472.

22. Beck AT, Ward CH, Mendelson M, Mock J, Erbaugh J. An inventory for measuring depression. Arch Gen Psychiatry. 1961;4:561-571.

23. Beck A, Steer R, Brown G. Manual for the BDI-II. San Antonio, TX: Psychological Corporation; 1996.

24. Brand S, Kirov R. Sleep and its importance in adolescence and in common adolescent somatic and psychiatric conditions. Int J Gen Med. 2011;4:425-442.

25. Kotagal S. Narcolepsy in children. Semin Pediatr Neurol. 1996;3(1): 36-43.

26. Spanos NP, Mcnulty SA, Dubreuil SC, Pires M, Burgess MF. The frequency and correlates of sleep paralysis in a university sample. J Res Pers. 1995;29(3):285-305.

27. Girard TA, Cheyne JA. Timing of spontaneous sleep-paralysis episodes. J Sleep Res. 2006;15(2):222-229.

28. Parker JD, Blackmore SJ. Comparing the content of sleep paralysis and dream reports. Dreaming. 2002;12(1):45-59.

29. Hartmann E, Harrison R, Zborowski M. Boundaries in the mind: past research and future directions. N Am J Psychol. 2001;3(3):347-368.

30. Reinsel R, Antrobus J, Wollman M. Waking fantasy. The Neuropsychology of Sleep and Dreaming. 1992:157-184.

31. Hall CS, Van de Castle RL. The Content Analysis of Dreams. New York, NY: Appleton-Century-Crofts; 1966.

32. Kotorii T, Kotorii T, Uchimura N, et al. Questionnaire relating to sleep paralysis. Psychiatry Clin Neurosci. 2001;55(3):265-266.

33. Watson D. Dissociations of the night: individual differences in sleeprelated experiences and their relation to dissociation and schizotypy. J Abnorm Psychol. 2001;110(4):526-535.
Neuropsychiatric Disease and Treatment

\section{Publish your work in this journal}

Neuropsychiatric Disease and Treatment is an international, peerreviewed journal of clinical therapeutics and pharmacology focusing on concise rapid reporting of clinical or pre-clinical studies on a range of neuropsychiatric and neurological disorders. This journal is indexed on PubMed Central, the 'PsycINFO' database and CAS,

\section{Dovepress}

and is the official journal of The International Neuropsychiatric Association (INA). The manuscript management system is completely online and includes a very quick and fair peer-review system, which is all easy to use. Visit http://www.dovepress.com/testimonials.php to read real quotes from published authors. 